\title{
Analysis of multitrophic plankton assemblages in the Lagoon of Venice
}

\author{
Vinko Bandelj ${ }^{1}$, Giorgio Socal ${ }^{2}$, Young-Seuk Park ${ }^{3}$, Sovan Lek ${ }^{4}$, Joan Coppola ${ }^{2}$, \\ Elisa Camatti ${ }^{2}$, Elisa Capuzzo ${ }^{2}$, Luisella Milani ${ }^{5}$, Cosimo Solidoro ${ }^{1, *}$ \\ ${ }^{1}$ Istituto Nazionale di Oceanografia e di Geofisica Sperimentale (OGS), Borgo Grotta Gigante - Briščiki 42/c, \\ Sgonico - Zgonik (TS) 34010, Italy \\ ${ }^{2}$ ISMAR CNR Istituto Scienze Marine, Sezione di Venezia, Castello 1364/a, Venezia 30122, Italy \\ ${ }^{3}$ Department of Biology, Kyung Hee University, Hoegi-dong, Dongdaemun-gu, Seoul 130-701, ROK \\ ${ }^{4}$ Laboratoire Dynamique de la Biodiversité (LADYBIO), UMR CNRS 5172, Université Paul Sabatier, 118 route de Narbonne, \\ Toulouse cédex 4 31062, France \\ ${ }^{5}$ Regional Environment Protection Agency of Friuli Venezia Giulia (ARPA FVG), Osservatorio Alto Adriatico, Via Cairoli 14, \\ Palmanova (UD) 33057, Italy
}

\begin{abstract}
The paper illustrates the spatial and temporal succession of multitrophic plankton assemblages in the Lagoon of Venice and relates them to biogeochemical properties. Five communities were identified by recognizing patterns of co-occurrence of phyto-, protozoo- and metazooplankton organisms through a classification procedure combining self-organizing maps and cluster analysis. The complexity of time and space co-variation of 47 plankton taxa was thus compressed to the variation of only one qualitative variable. Biogeochemical observations provided information for an ecological description of the environment in which different biocenoses develop. Our results provide an objectively derived typology of plankton assemblages and an ideal representation of their typical succession in time and space. This can be used to better understand the dynamics of the plankton community, and as a reference term for the identification and evaluation of anomalous situations, as required by implementation of the EU Water Framework Directive. Our results indicated the importance of seasonality in ruling succession among different biocenoses. River inflows, exchanges with the sea, remineralization processes and benthic-pelagic coupling were all important factors in shaping plankton communities and defining their spatial extension. Autotrophy prevailed in late winter to spring in inner areas of the lagoon, whereas heterotrophy prevailed in late summer to early winter and generally in areas close to the inlets. Diatoms, including resuspended benthic species, dominated autotrophic compartments, and copepods Acartia spp. were the most abundant mesoplankton organisms. Our results also point out the prominent role of protozooplankton in the trophodynamic of the Lagoon of Venice.
\end{abstract}

KEY WORDS: Plankton communities · Self-organizing map · Lagoon of Venice $\cdot$ Trophic food webs · EU Water Framework Directive · Typology · Microzooplankton

\section{INTRODUCTION}

The purpose of the present study was to (1) objectively identify co-occurrence patterns of organisms belonging to different trophic levels, i.e. identify which and how many are the typical plankton assemblages in the lagoon area; (2) derive the spatio-temporal suc- cession of these plankton assemblages; and (3) identify environmental variables shaping plankton assemblages.

These goals are crucial because they might provide both a deeper understanding of ecosystem functioning and information on water quality status. Indeed, in pelagic marine ecosystems, plankton represents the base of trophic chains, and the structure of plankton 
communities (composition, abundance and biomass) is important in defining paths, modality and transfer efficiency of mass and energy flows inside trophic webs. Plankton is also a key element in the assessment of aquatic ecosystems' quality status (Reynolds 1997) because of its trophic role and relatively fast response to alterations of environmental variables, which might not be emphasized by longer living biological elements, such as benthic organisms (Gibson et al. 2000).

Integrated analysis of multitrophic plankton assemblages are particularly valuable: they consider different types of relationships occurring in real biocenoses at the same time, such as competition and predation, which cannot be accounted for when the analysis is limited to a single species or trophic level, but that concur in defining the realized niches of interacting populations. In addition, while the presence of a single species might provide some information on environmental conditions, much less information can be inferred from the absence of a single species, which might be due to many different reasons (Jongman et al. 1995). Furthermore, the lack of ecophysiological studies on singlespecies-environment relationships heavily limits the interpretation of plankton diversity at the species level (Cloern \& Dufford 2005).

The objectives of this paper are also of primary importance in view of new regulations enforced by water conservation authorities (i.e. the EU Water Framework Directive 2000/60/EC available at: http:// ec.europa.eu/environment/water/water-framework/ index_en.html and EU Marine Strategy Framework Directive 2008/56/EC available at: http://ec.europa.eu/ environment/water/marine/index_en.htm), since these require both the definition of the typology of water bodies and the identification of reference conditions for each of the typology classes. However such requirements pose the problem of how to define and characterize such classes objectively, i.e. how many classes there are, where the boundaries among classes are, how to associate each class to a given point in space and time, and how to identify species assemblages characterizing each class.

The methodology here proposed is a possible answer to these very questions. We used a combination of a self-organizing map (SOM) (Kohonen 1982, 2001) and cluster analysis in order to analyze the abundances of phyto-, protozoo- and metazooplankton, as well as their distribution along gradients of biogeochemical variables. SOM has several advantages as compared to other numerical techniques commonly used in classification or gradient analysis: it does not rely on any particular a priori assumption on dataset structure, is not affected by the presence of outliers, and can efficiently cope with datasets including a reasonable number of missing data. SOM was already successfully used in several ecological applications (e.g. Lek \& Guégan 1999, Giraudel \& Lek 2001, Park et al. 2004), as well as in oceanographic (Richardson et al. 2002, Liu et al. 2006) and biogeochemical (Solidoro et al. 2007) ones. The use of the 2-step procedure with application of a hierarchical clusterization method to SOM results accounts for some weak points of the SOM algorithm (Park et al. 2004, Solidoro et al. 2007).

Our results enable us to develop an objectively derived typology of plankton assemblages, which can be used as a reference term for different moments and areas of the lagoon, and therefore for identification and evaluation of anomalous situations, as required by the implementation of the EU Water Framework Directive.

\section{MATERIALS AND METHODS}

Study site. The study site was the Lagoon of Venice, which is a large Mediterranean lagoon with an area of ca. $500 \mathrm{~km}^{2}$, located in the Northern Adriatic Sea (Fig. 1). It is surrounded by heavily inhabited shores, important coastal industrial areas, fisheries, mariculture, and tourist activities, and it encloses sites of great historical and artistic value (Ravera 2000). There are 12 major tributaries, which carry annually ca. $35 \mathrm{~m}^{3} \mathrm{~s}^{-1}$ of freshwater in the lagoon (Zuliani et al. 2005). Nitrogen and phosphorus loads are in order of $4000 \mathrm{TN} \mathrm{yr}^{-1}$ and

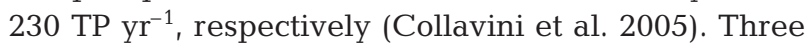
inlets connect the lagoon to the sea, with a yearly averaged exchange of ca. $8000 \mathrm{~m}^{3} \mathrm{~s}^{-1}$ (Gačić et al. 2005). A complex network of channels, originating from the inlets, divides the lagoon in 4 major subbasins and in a large number of landscape units. Average water depth is less than $1 \mathrm{~m}$ in the flats, while it reaches up to $10 \mathrm{~m}$ in channels connecting the 3 inlets with Venice and the Marghera harbour. General circulation results from the superposition of tide, wind, and topographic control (Solidoro et al. 2004, Gačić et al. 2005), and the effective renewal of water is on the order of a few days for the area closest to the inlets and up to $30 \mathrm{~d}$ for the inner area (Solidoro et al. 2004, Cucco \& Umgiesser 2006). Due to the complexity of interactions and the variety of stressors simultaneously occurring, the lagoon presents high variability in most environmental parameters and high habitat heterogeneity (Ravera 2000). Indeed, different partitions have been proposed in order to identify homogeneous areas (Solidoro et al. 2004, Marchini \& Marchini 2006).

Field data. Data were collected monthly at 6 sites inside the lagoon and at 1 site near the shore just outside the Lido inlet (Fig. 1) within the programme ICSEL (Integrazione delle Conoscenze del Sistema Ecologico Lagunare), funded by the Venice Water Autorithy through the Consorzio Venezia Nuova. The 
programme started in April 2003 and lasted 1 yr. All the lagoon sites were located in shallow waters. Each sample reported abundances of phytoplankton, microzooplankton and mesozooplankton organisms, as well as physical and chemical parameters related to water quality.

Phytoplankton samples were collected in $250 \mathrm{~cm}^{3}$ glass dark bottles, and fixed with $10 \mathrm{~cm}^{3}$ of $20 \%$ hexamethylentetramine-buffered formaldehyde (Throndsen 1978). Counts were taken according to Utermöhl's (1958) method, using an inverted microscope (Zeiss Axiovert 35) after 2 to $10 \mathrm{~cm}^{3}$ subsamples had settled for $24 \mathrm{~h}$ (Zingone et al. 1990). Species composition for marine phytoplankton was defined as in Tomas (1997) and references therein.

Microzooplankton samples were collected in $2 \mathrm{dm}^{3}$ plastic bottles and fixed with $80 \mathrm{~cm}^{3}$ of sodium tetraboratebuffered formaline. A first settling of each sample was performed reducing volumes to $200 \mathrm{~cm}^{3}$ (Fonda Umani \& Milani 1990); then the samples were mixed and filtered across a $20 \mu \mathrm{m}$ net. Subsamples of variable volume (from 5 to $50 \mathrm{~cm}^{3}$ ) were coloured with red Bengala and analysed on the whole settling chamber area at 200 to $320 \times$ (i.e. ocular $10 \times$, objective 20 and $32 \times$ ). Counts were performed after Utermöhl (1958) and

Fonda Umani \& Milani (1990).

Mesozooplankton samples were collected with a Clarke Bumpus horizontal sampler (200 $\mu \mathrm{m}$ net); the catch content was poured in $250 \mathrm{~cm}^{3}$ plastic bottles and fixed with sodium tetraborate-buffered formaline (Zunini Sertorio 1990a). Counts were performed after a resuspension of the sample with $200 \mathrm{~cm}^{3}$ of filtered seawater with a Zeiss 125 stereomicroscope using a Kolkwitz open chamber (Zunini Sertorio 1990b) on $5 \mathrm{~cm}^{3}$ significative subsamples (at least 4 for each sample).

In the dataset, we identified 97 taxa (species or genus) of phytoplankton, 66 of microzooplankton and 62 of mesozooplankton. However, to reduce the bias from rare species, only 47 taxa, which were present in at least $5 \%$ of the samples, were considered.

Temperature, salinity, dissolved oxygen, $\mathrm{pH}$ and redox potential (Eh) have been measured in situ using a CTD Idronaut Ocean Seven 316 Multiprobe. Alkalinity has been obtained after a potentiometric titration with HCL (APHA 1998), total suspended solids with a gravimetric method (APAT IRSA-CNR 2003). Inorganic nutrients $\left(\mathrm{NH}_{3}, \mathrm{NO}_{\mathrm{x}}\right.$ and $\left.\mathrm{PO}_{4}\right)$ were analysed using an autoanalyzer Micromat 1000 Systea (Strickland \& Parsons 1972), following APAT IRSA-CNR (2003). Dissolved organic nitrogen (DON) and dissolved organic phosphorus (DOP) were determined with oxidation of the samples using potassium persulfate and obtaining DON and DOP concentrations after subtraction of inorganic fractions (ICRAM 2001). Particulate organic carbon (POC) was determined using a $\mathrm{CHN}$ analyser (EPA 1997) and total organic carbon (TOC) after oxidation at $950^{\circ} \mathrm{C}$. Dissolved organic carbon (DOC) concentrations were obtained after subtraction of POC fraction (APAT IRSA-CNR 2003). Chlorophyll a (chl a) and phaeopigments samples were analysed with spectrophotometric methods after IRSA (1990). A list of 17 chemical and physical variables is given in Table 1.

Modelling methods. A SOM (Kohonen 1982, 2001) is a competitive, unsupervised, self-adapting artificial neural network which provides a topology preserving 
Table 1. Medians of physical and chemical variables (not used in self-organizing map, SOM, training). Highest median values are in bold, lowest in italics

\begin{tabular}{|c|c|c|c|c|c|c|c|}
\hline Variable & Abbreviation & Unit & Cluster 1 & Cluster 2 & Cluster 3 & Cluster 4 & Cluster 5 \\
\hline Temperature & temp & ${ }^{\circ} \mathrm{C}$ & 9.6 & 23.7 & 26.4 & 25.3 & 8.1 \\
\hline Salinity & sal & psu & 29.6 & 31.2 & 33.4 & 36.3 & 33.7 \\
\hline Oxygen saturation & OXSAT & $\%$ & 97.8 & 96.7 & 94.0 & 88.9 & 94.9 \\
\hline Dissolved oxygen & DOX & ppm & 9.53 & 7.01 & 6.42 & 6.13 & 8.90 \\
\hline $\mathrm{pH}$ & $\mathrm{pH}$ & & 7.92 & 8.05 & 8.03 & 7.99 & 7.97 \\
\hline Redox potential & Eh & $\mathrm{mV}$ & 405 & 402 & 384 & 412 & 405 \\
\hline Alkalinity & alk & $\mathrm{mE} \mathrm{dm}{ }^{-3}$ & 3100 & 3000 & 2900 & 3000 & 2900 \\
\hline Total suspended solids & TSS & $\mathrm{mg} \mathrm{dm}{ }^{-3}$ & 15.0 & 14.4 & 30.4 & 22.7 & 14.4 \\
\hline Ammonium & $\mathrm{NH}_{4}$ & $\mu \mathrm{g} \mathrm{dm}^{-3}$ & 67.1 & 7.1 & 5.5 & 8.0 & 97.2 \\
\hline Nitrates & $\mathrm{NO}_{\mathrm{x}}$ & $\mu \mathrm{g} \mathrm{dm}^{-3}$ & 500.0 & 93.1 & 44.6 & 18.5 & 290.0 \\
\hline Dissolved organic nitrogen & DON & $\mu \mathrm{g} \mathrm{dm}^{-3}$ & 130.0 & 180.0 & 198.6 & 260.0 & 96.0 \\
\hline Phosphates & $\mathrm{PO} 4$ & $\mu \mathrm{g} \mathrm{dm}^{-3}$ & 5.00 & 5.10 & 3.57 & 4.06 & 3.20 \\
\hline Dissolved organic phosphorus & DOP & $\mu \mathrm{g} \mathrm{dm} \mathrm{m}^{-3}$ & 9.86 & 22.20 & 24.15 & 21.19 & 8.12 \\
\hline Particulate organic carbon & POC & $\mathrm{mg} \mathrm{dm} \mathrm{dm}^{-3}$ & 0.355 & 0.682 & 0.804 & 0.535 & 0.319 \\
\hline Dissolved organic carbon & DOC & $\mathrm{mg} \mathrm{dm} \mathrm{dm}^{-3}$ & 2.52 & 2.39 & 2.70 & 2.29 & 2.55 \\
\hline Chlorophyll a & chl a & $\mu g \mathrm{dm}^{-3}$ & 1.4 & 2.8 & 6.6 & 2.8 & 1.1 \\
\hline Phaeopigments & phaeo & $\mu \mathrm{g} \mathrm{dm} \mathrm{dm}^{-3}$ & 0.8 & 0.4 & 1.6 & 1.3 & 0.4 \\
\hline
\end{tabular}

non-linear projection of multivariate data sets in a lower dimensional, usually 2-dimensional, space (map). The final result is a clusterization of all samples in a given number of groups and the identification of one 'best descriptor' for each of the groups. The classification is based on an iterative algorithm which takes into consideration similarity among samples, as described by the parameters associated with the samples. The best descriptors are not the median nor the average, nor the results of any simple operation performed on the samples associated with a group, but they are a result of the learning phase. Furthermore, the best descriptors are ordered on the low-dimensional space, based on their multivariate similarity. Therefore, a SOM acts at the same time as a classification, ordination, and information compression procedure.

The method does not need any a priori assumption on the distribution of the data, nor a subdivision of the data in input and output datasets, as in supervised neural networks. In unsupervised neural networks the training phase is a process in which the network learns to classify by recognizing similar patterns in the samples.

The first step in a SOM algorithm is the choice of the map units' number and how they are arranged on the map grid. Then, an $n$-dimensional model vector is associated to each map unit, where $n$ is the number of variables in the input sample, so that each unit can be seen as a synthetic sample. Initial values are assigned either randomly or in agreement with purposely designed algorithms (e.g. the linear initialization, Kohonen 2001). The ensemble of the $j$-th components of all model vectors defines the $j$-th component plane of the map, which depicts the distribution of the components along the SOM. Then the learning phase begins: (1) an observed sample is drawn from the input dataset and compared to every map unit; (2) the map unit with the lowest distance (usually Euclidean distance) from the input data is identified and labeled best-matching unit (BMU); (3) the values of the BMU and, to a smaller extent, of a specified number of neighboring map units are adjusted to become more similar to the input sample according to a predefined learning function:

$$
m_{i}(t+1)=m_{i}(t)+h\left(d_{c i} \alpha(t)\right)\left[x(t)-m_{i}(t)\right]
$$

where $m_{i}$ is the $i$-th map unit, and $h$ is a distance function, which decreases with increasing distance $d_{c i}$ between the map unit $c$ (BMU) and the map unit $i$, and with decreasing learning rate factor $\alpha(t)$. The learning rate factor decreases with increasing number of learning cycles $t$. Then (4) the procedure (1) to (3) is repeated for all data, and (5) the whole procedure (1) to (4) is repeated several times until a quasi steady condition is reached. During the first iterations (rough training phase) the number of adjusted neighbouring units and the learning rate are large; thus, the convergence is fast and a global ordination is achieved. In the last iterations (fine-tuning phase) the learning rate is very small and only the BMU is updated at each step, causing a local adjustment of the values on the SOM. In the end, each input sample is linked to one map unit that best represents it, and each map unit is linked to a list of observed samples. Map units close in the 2-dimensional grid are similar, and thus a local order arises on the map and the spatial distribution of each variable along its component plane is as smooth as possible.

There is no theoretical proof of convergence (Kohonen 2001), and different replicates of the learning procedure result in slightly different outputs because of data presentation to model vectors in random order. Thus, the whole procedure is run many times and the 
best solution retained. Quality measures for accuracy of the SOM (mean quantization error) (Sun 2000) and for goodness of local ordination (topographic error) (Kaski 1997) can be used as guidelines. Also, there is no theoretical rule for choosing the size of the map, even if an intermediate level of compression is often preferred. In fact, while a map which is too large is not very useful in interpretation, because there are too many units and few samples for unit, a map which is too small might not leave enough degrees of freedom and forcedly associate with the same group data that are not similar. Most of the available software packages (including SOM-Toolbox for Matlab used in the present study) provide empirical suggestions and default options for the selection of map size and optimized values for the training parameters (Vesanto et al. 1999).

In our application data on taxa abundances were used in the SOM training, while physical and chemical parameters were used for interpretation of the trained map. Prior to analysis the species abundances were logarithmically transformed [ln(abundance +1$)$ ] to reduce variation and skewness of abundance and normalized to the interval $(0,1)$ (Legendre \& Legendre 1998) to give the same weight to different taxa regardless of their abundance. Map units were initialized with linear initialization (Kohonen 2001), since this gives a quicker convergence (Liu et al. 2006), and SOM toolbox default values were used for other parameters (Vesanto et al. 1999).

Each map unit represented a different synthetic plankton assemblage. In order to achieve a clearer and more robust representation of the system dynamics, clusters of similar units were considered rather than the units themselves, i.e. to associate synthetic plankton assemblages to pieces of the map. Therefore, a cluster analysis was applied on non-empty map units (Vesanto \& Alhoniemi 2000). The hierarchical clustering algorithm was used, based on Ward's minimum variance (Legendre \& Legendre 1998).

Environmental variables, dominant and characteristic taxa. After training of the SOM, dominant and characteristic taxa were discriminated using the values associated with map units. In each cluster the taxa defined as dominant were those which presented the highest abundances. Thus, we can argue that dominant taxa substantially contributed to the biomass cycling and to the characterization of the most important trophic relations. In order to identify these taxa, the median values of the most abundant phototrophic organisms of each cluster were compared and the one with the lowest value identified. Then all taxa with an abundance higher than that value were considered as dominant. In this way different clusters had different numbers of dominant taxa. To obtain characteristic taxa of each cluster all taxa values were subdivided in 5 classes of 20 percentiles, and the median value of each taxon in each cluster was assigned to these classes. In each cluster the characteristic taxa were those falling in the highest class and thus showing the maximum abundances compared to the rest of the map. The abundances of the characteristic taxa could be much smaller than those of dominant species, so their role in energy transfers through the trophic food webs might not be relevant. Conversely, their presence could be seen as an indicator of particular environmental conditions. Taxa that were both dominant and characteristic played a very prominent role in the biologic interpretation of their assemblages.

Since in SOM a list of samples is associated with each map unit, it was also possible to compute and associate with each unit a representative value of environmental variables not used in the SOM training (Park et al. 2003). The ordination and clustering were defined over plankton abundances; therefore, differences among representative values of environmental variables provided information about the environmental requirements of different plankton assemblages, as in indirect gradient analysis, and the ensemble of environmental variables associated with a cluster represented a community multivariate ecological space. The list of samples associated with each map unit also made it possible to retrieve information on spatial and temporal occurrences of each cluster (plankton community), i.e. about months and sampling sites where each cluster was mainly present.

\section{RESULTS}

We trained 5 maps of different sizes, each one with 10 replicates. We chose the map with 20 units arranged in a $5 \times 4$ rectangular grid (Fig. 2), which had a mean quantization error of 1.37 and a topographic error of 0.00 . In this way we achieved a 4 -fold compression of the information stored in the input dataset. This was consistent with the main goal of the present study, i.e. the identification of a small number of characteristic plankton communities. Larger maps did not show a significant reduction of the mean quantization error values.

A visual inspection of the map (Fig. 2) revealed that most samples fell in map units along the borders of the map, and suggested a first dividing of the map in different areas. A clear temporal structure emerged, with a counterclockwise distribution of months samples on the map, from cold months in the upper part of the map to warm months in the lower part. The existence of a spatial structure was less clear; however, a gradient from northern inner areas to southern marine areas of 
a

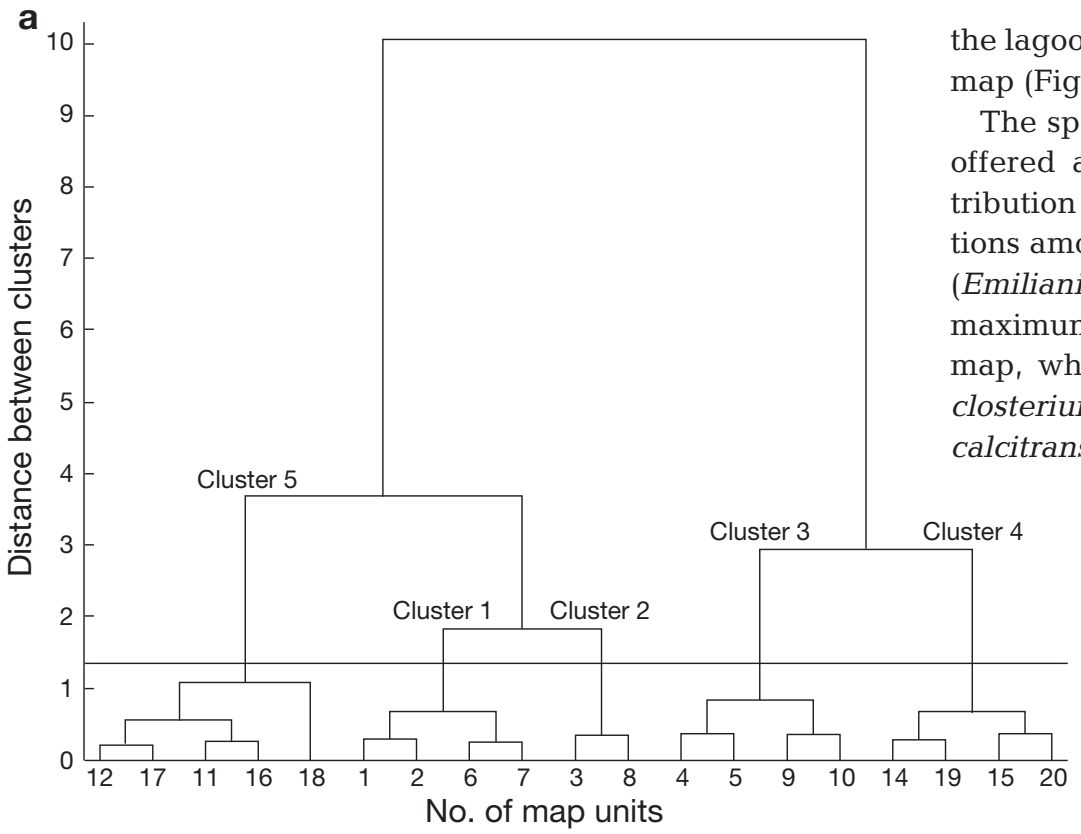

b

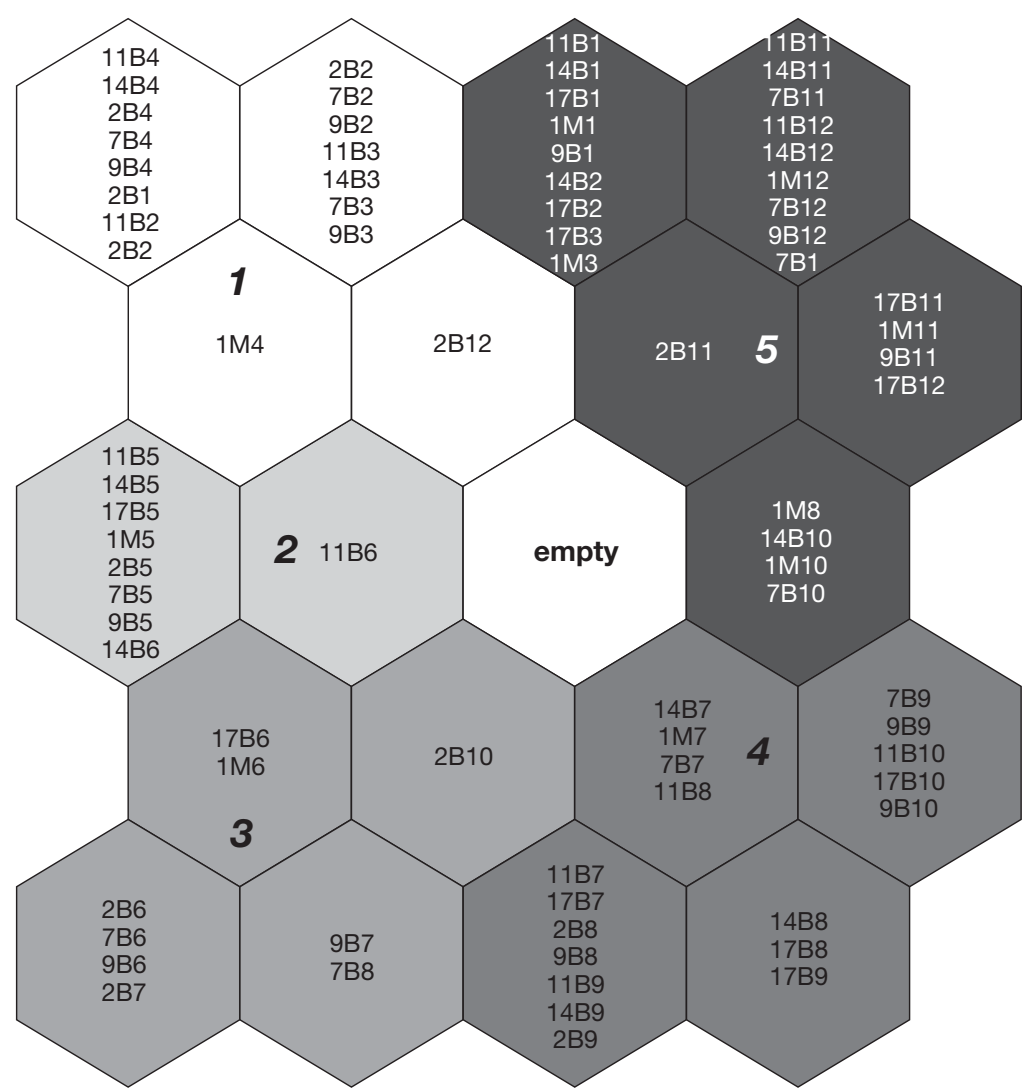

Fig. 2. (a) Dendrogram on map units. Units go from top to bottom and from left to right on the map. Map unit 13 was excluded from clusterization because it had no sample associated. (b) Ordination of samples on the selforganizing map (SOM). Each sample is indicated by the name of the sampling site and the number of month of sampling (e.g. sample of December in Stn 2B is 2B12). Clusters are shown with white/shades of gray and corresponding number the lagoon could be recognized from left to right on the ap (Fig. 2).

spatial distribution of 47 taxa on the SOM units inst indication of the spatio-temporal disEmiliania huxleyi and Oithona spp.) showed their ximum values in the upper right corner of the SOM , Melosira sp., Cyclotella sp., Chaetoceros Asterionellopsis glacialis, Didinium spp. and Acartia margalefi) with the maximum in the lower left corner and the minimum in the upper right corner.

Cluster analysis divided the SOM units in 5 groups (Fig. 2). The dendrogram separated first the upper central (Clusters 1, 2 and 5) and lower parts (Clusters 3 and 4 ) of the SOM. Fig. 4c details the association between samples and clusters and illustrates the succession of clusters in time and space. In April 2003 all valid samples belonged to Cluster 1. In May Cluster 1 was replaced by Cluster 2 . In June all samples fell in Cluster 3, except Stns 11B and 14B. Cluster 3 was replaced by Cluster 4 in July, and this cluster covered the main part of the lagoon until September. In August Cluster 3 characterized Stn 7B, while Stn $1 \mathrm{M}$ belonged to Cluster 5. In September all valid samples belonged to Cluster 4 . In October one sample (Stn 2B) was associated with Cluster 3 , three samples to Cluster 4 and three to Cluster 5. In November Cluster 5 covered all the study sites, being the dominant cluster until January 2004. In December and November Cluster 1 reappeared in Stn 2B and then progressively spread in the lagoon until March, when Cluster 5 lasted only in Stns 17B and 1M.

The 1-way ANOVA on environmental variables in the 5 clusters gave non-significant differences (F-test, $\mathrm{p}>0.05)$ for $\mathrm{pH}$, Eh, alkalinity, phosphates and DOC. Other environmental variables, i.e. temperature, salinity, oxygen concentration and saturation, TSS, $\mathrm{NO}_{\mathrm{x}}, \mathrm{NH}_{4}, \mathrm{DON}, \mathrm{DOP}, \mathrm{POC}$, and pigments (Table 1), showed differences among clusters, suggesting the existence of relationships between those variables and plankton assemblages. Temperature, salinity and oxygen values were in agreement with clusters' spatio-temporal interpretation: temperature was high in late spring to early fall clusters, while it 


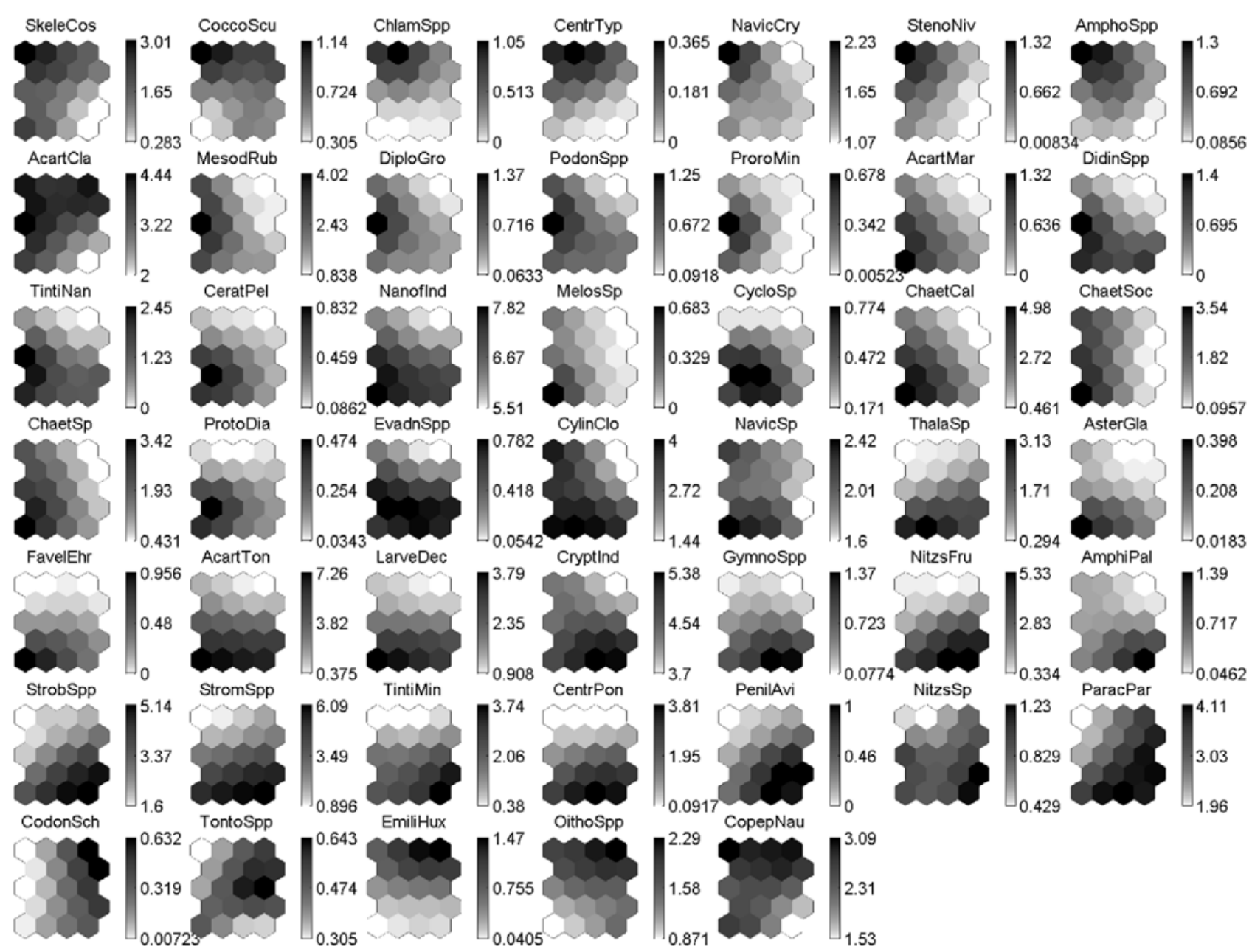

Fig. 3. Component planes of 47 plankton taxa used in self-organizing map (SOM) training. Log-transformed abundances are linked to white/shades of gray by corresponding color bars. Full species names given in Table 2

was low in late fall to early spring clusters; salinity was lowest in Cluster 1, while it had an extremely high median value in Cluster 4, due to a small amount of rainfall and extensive drought which took place in summer 2003; medians of dissolved oxygen and oxygen saturation were almost inversely related to temperature. Wide variation ranges characterized inorganic nutrients because of spatial and temporal variability of their different sources. Ammonium and nitrates were higher and more variable in Clusters 1 and 5 (late fall to early spring), while they were lower and less variable in Clusters 2, 3 and 4 (late spring to early fall), likely because of uptake from phytoplankton and low freshwater discharges. DON and phosphorus were on the contrary high in Clusters 2, 3 and 4 and low in Clusters 1 and 5. POC and pigments (chl $a$ and phaeopigments) increased steadily from Cluster 1 to the highest values in Cluster 3, then decreased to the lowest values in Cluster 5. Variability was higher during late spring and summer months.
A description of the space and time variabilities of the main biogeochemical properties is given in Fig. 4 . Fig. 4a shows the monthly evolution of dissolved inorganic nitrogen (DIN) (sum of $\mathrm{NO}_{\mathrm{x}}$ and $\mathrm{NH}_{4}$ ), DON, chl $a$ and salinity obtained by weight averaging the values of the clusters associated with each month. Fig. $4 \mathrm{~b}$ shows the space variation of the same variables, obtained by weight averaging the values of clusters associated with each site.

In Table 2 characteristic taxa of the 5 communities are listed. Table 3 groups taxa in dimension and trophic classes, as well as according to higher taxonomic levels. Cluster 1 was the only cluster with more dominant autotrophs than heterotrophs and, together with Cluster 5, it was the poorest in species diversity and biomass. In Cluster 2 there were 8 characteristic taxa, and the number of dominant taxa increased (the number of microplankton- and mesoplanktondominant taxa doubled), while the highest increase was due to heterotrophs. Cluster 3 had the highest 
Fig. 4. (a,b) Weighted medians of salinity, chlorophyll a (chl a), dissolved inorganic nitrogen (DIN, sum of $\mathrm{NO}_{\mathrm{x}}$ and $\mathrm{NH}_{4}$ ) and dissolved organic nitrogen (DON) in (a) time and (b) space. (c) Distribution of clusters in time and space. Numbers in (c) refer to clusters; $\mathrm{x}$ : missing samples. Occurrences of 'marine' Clusters 4 and 5 are shaded in dark gray, occurrences of 'internal' Clusters 1 and 3 in light gray. $(a, b)$ First axis indicates concentrations of chl $a$ in $\mu \mathrm{g} \mathrm{dm}^{-3}$; second axis indicates salinity values in psu and the third indicates concentrations of DIN and DON in $\mu \mathrm{g} \mathrm{dm}^{-3}$. Values were computed first listing all samples of all clusters present in each month or sampling site, repeated by the frequency of each cluster. Then, medians were identified on these lists of samples

DIN and DON $\left(\mu \mathrm{g} \mathrm{dm}^{-3}\right)$

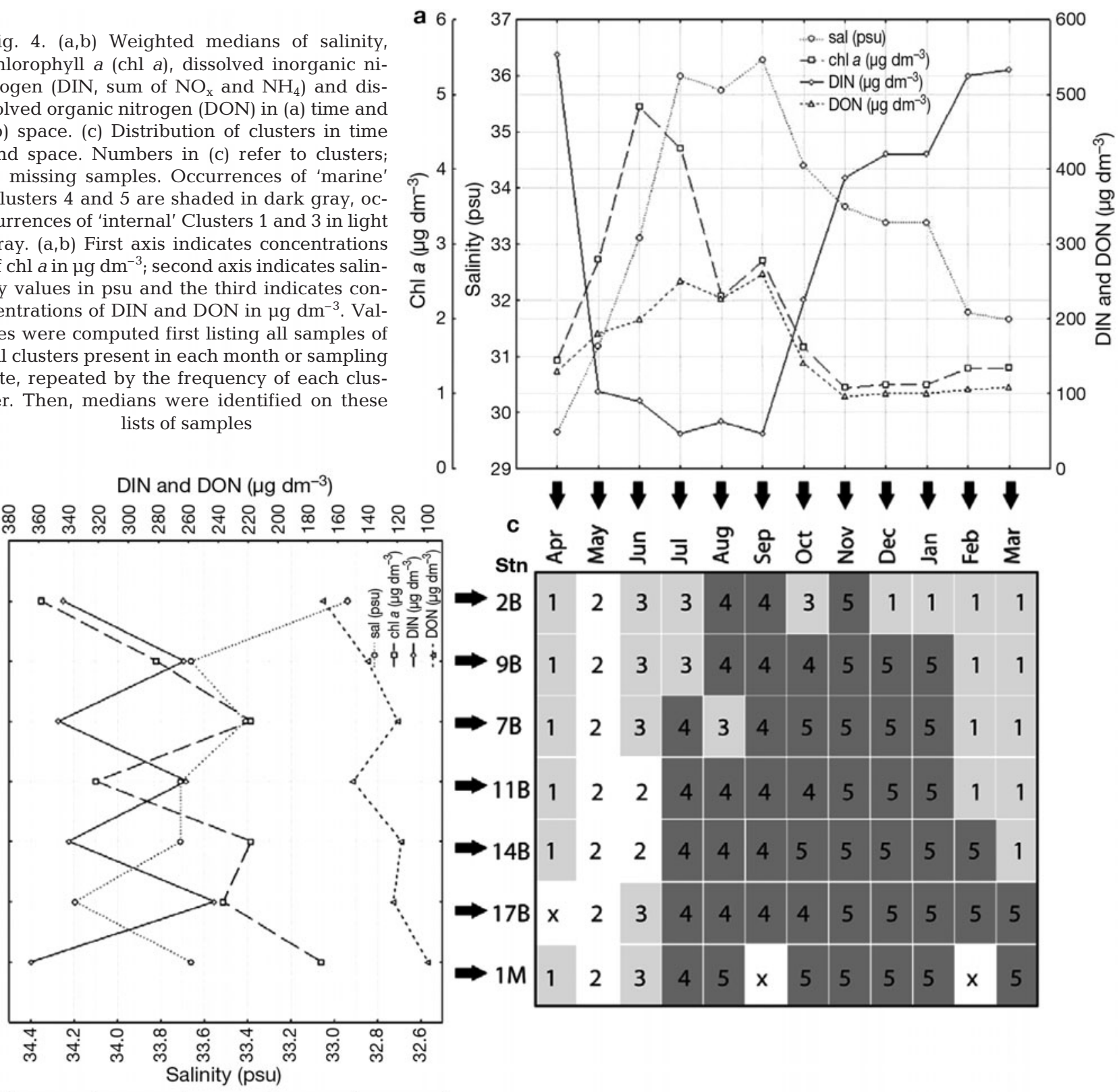

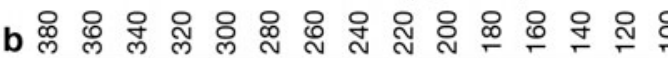

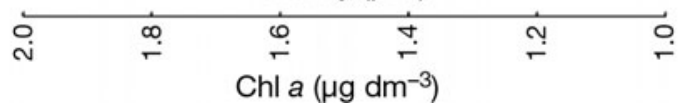

number of dominant taxa and the highest overall median, as well as the highest number of characteristic taxa. Cluster 4 showed a reduction in the number of dominant taxa for all dimensions and trophic classes. Cluster 5 showed the lowest number of dominant taxa and the lowest overall median. It also had the lowest number of characteristic taxa and the highest number of taxa showing very low values.

Median abundances of flagellates, i.e. nanoflagellates and cryptophyceae, were always much higher than those of the other taxa (Table 3). They reached maximum values in Clusters 3 and 4, respectively, whereas both had minimum values in Cluster 5 .
The autotrophic community was dominated by diatoms. Their blooms included opportunistic species (Skeletonema costatum and Nitzschia frustulum) and neritic species adapted to a wide range of salinity (Chaetoceros). The only diatom dominant in all 5 clusters was Cylindrotheca closterium, and therefore it was very important for the lagoon ecosystem throughout the year. From Cluster 1 to 4 (i.e. from April to October) nanoplankton single-cell diatoms ( $N$. frustulum) prevailed on microplankton or colonial diatoms ( $S$. costatum), and resuspended benthic diatoms ( $N$. frustulum and $C$. closterium) prevailed on pelagic ( $S$. costatum, C. socialis). In late summer the 
Table 2. Characteristic taxa of each cluster, i.e. taxa showing very high abundances compared to their median values on the entire self-organizing map (SOM)

\begin{tabular}{|lllll|}
\hline Cluster 1 & Cluster 2 & Cluster 3 & Cluster 4 & Cluster 5 \\
\hline Skeletonema costatum & Acartia clausi & Acartia margalefi & Cryptophyceae & Codonellopsis schabii \\
Cocconeis scutellum & Mesodinium rubrum & Didinium spp. & Gymnodinium spp. & Tontonia spp. \\
Chlamydodon spp. & Diplopsalis group & Tintinnopsis nana & Nitzschia frustulum & Emiliania huxleyi \\
Centropages typicus & Podon spp. & Cerataulina pelagica & Amphiprora paludosa Oithona spp. \\
Navicula cryptocephala & Prorocentrum minimum & Nanoflagellates & Strobilidium spp. & Nauplii of copepods \\
Stenosemella nivalis & Acartia margalefi & Melosira sp. & Strombidium spp. \\
Amphora spp. & Didinium spp. & Cyclotella sp. & Tintinnopsis minuta \\
& Tintinnopsis nana & Chaetoceros calcitrans & Centropages ponticus \\
& & Chaetoceros socialis & Penilia avirostris \\
& & Chaetoceros sp. & Nitzschia sp. \\
& & Protoperidinium diabolus & Paracalanus parvus \\
& Evadne spp. & \\
& Cylindrotheca closterium & \\
& Navicula sp. & \\
& Thalassiosira sp. & \\
& Asterionellopsis glacialis & \\
& Favella ehrembergi & \\
& Acartia tonsa & \\
& Larvae of decapods & \\
& &
\end{tabular}

Table 3. Medians of log-transformed abundances and number of dominant taxa in each cluster. Dominant taxa are grouped by dimension classes, trophic classes and higher level taxonomic groups. MED: median; DOM TX: no. of dominant taxa

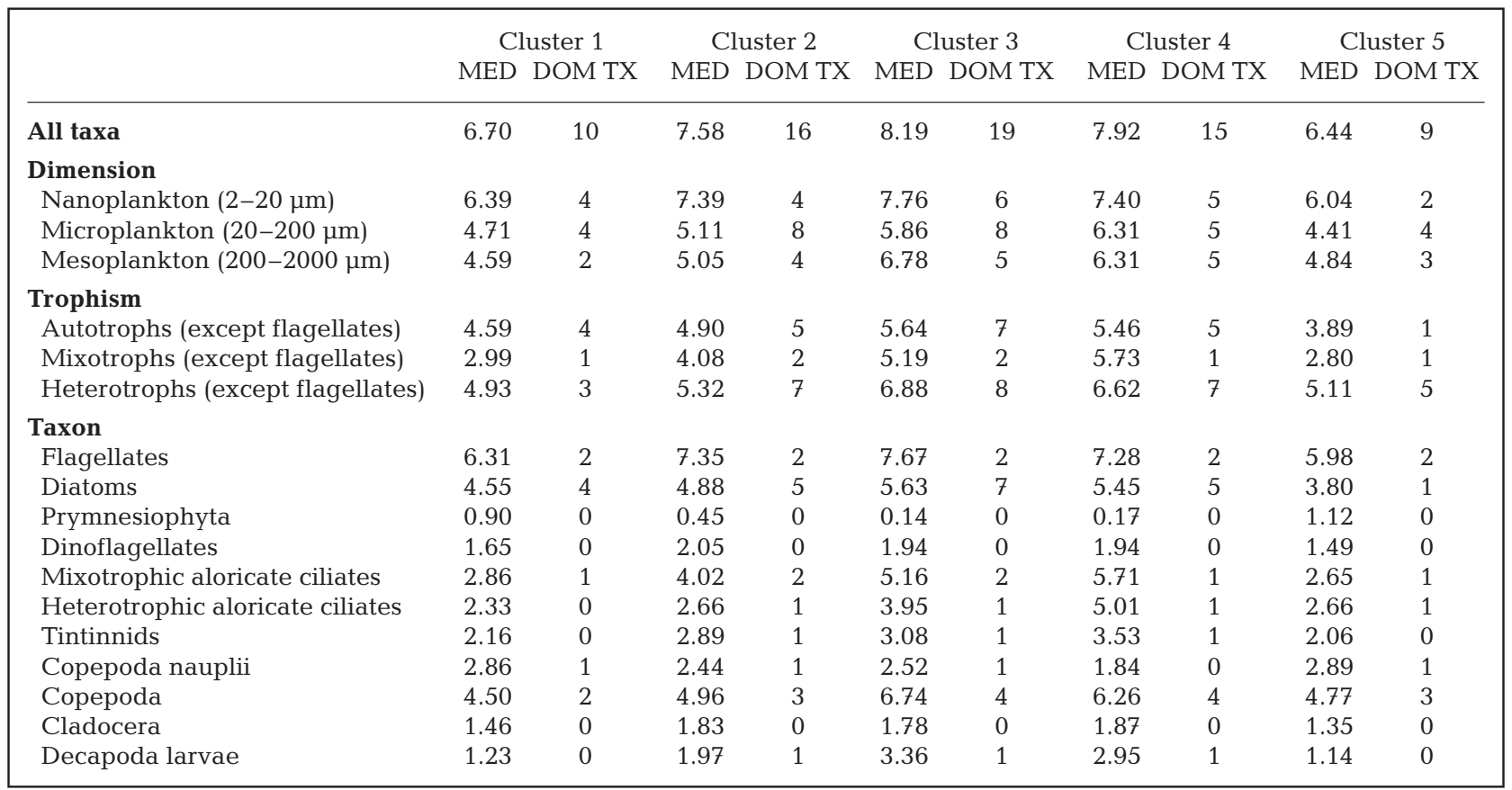

highest abundances of diatoms in the water column were associated with small benthic species, likely brought to pelagic lifestyle by perturbations induced by harbour activities and clam harvesting (Facca et al. 2002).

Protozooplankton organisms, and especially ciliates, played a prominent role in the trophodynamics of the Lagoon of Venice. The dominant taxa in the present study were: the mainly autotrophic Mesodinium rubrum, the mixotrophic ciliates Strombidium, the heterotrophic aloricate ciliate Strobilidium spp. and the tintinnids Tintinnopsis nana and T. minuta. M. rubrum were very abundant in late winter and spring. Strombidium were very abundant in late summer, when diatoms were small and mainly resuspended. Heterotrophic ciliates abundance increased with increasing 
temperature, organic nutrient concentrations and nanoplankton abundances. In late summer months they were probably the main consumers.

Copepods of the genus Acartia were dominant in the lagoon throughout the year, the most abundant species being $A$. clausi and $A$. tonsa, whose median values showed a clear inverse relation. A. clausi was dominant in all 5 clusters, with very reduced values in summer Clusters 3 and 4, while A. tonsa was not dominant in Clusters 5 and 1. Consequently, it was possible to argue that whereas $A$. tonsa is limited to confined inner areas and to warm months, where it shows extremely high abundances, A. clausi is always present in the lagoon at lower abundances, probably transported by inflowing marine waters. The turning points in their succession in the lagoon are May to June and October, similar to observations already reported for other systems (Jeffries 1962, Lawrence et al. 2004). The other cogener A. margalefi, which used to be the dominant copepod in polyhaline areas up to the 1990s, was never dominant, and the characteristic in Clusters 2 and 3 was present only at abundances much lower than those of $A$. tonsa. It is still unclear to which extent the introduction of $A$. tonsa, observed in the lagoon since 1992 (Bianchi et al. 2000), contributed to the decline of $A$. margalefi, given that there are also notices of the simultaneous disappearance of this species from other Italian estuarine and lagoon systems (Bianchi et al. 2000, Ribera D'Alcalà et al. 2004), indicating that larger scale changes might be responsible.

The highest abundances of copepods nauplii were from late fall to spring and early summer. Single-species counts would have been needed to clarify this information. Other abundant consumer species were Paracalanus parvus, the small cyclopoid copepods Oithona spp., and the large copepod Centropages typicus, frequently associated with Acartia clausi in Mediterranean coastal areas (Ribera D'Alcalà et al. 2004).

\section{DISCUSSION}

The SOM-based classification procedure identified 5 multitrophic plankton assemblages. They consitute an objectively derived typology and the space and time succession of clusters synthesized the typical succession among different biocenoses occurring in the lagoon.

In order to give an ecological meaning to cluster succession each of the clusters was interpreted in terms of the biological properties of its samples. Biogeochemical properties provided additional information for the description of the abiotic environment in which plankton communities develop.
An analysis of Fig. 4c highlights the importance of seasonality in ruling the transition from one pattern to another: Cluster 1 was present mainly in late winter to spring, Cluster 2 in late spring, Cluster 3 in early summer, Cluster 4 in late summer to early fall and Cluster 5 in late fall to winter. A seasonal succession can be recognized by weighted averages of clusters' biogeochemical properties (Fig. 4a), which indicates that there was a maximum of chl $a$ and POC all over the lagoon in spring, likely associated with plankton blooms sustained by nutrient-rich river outflow. Then, in late spring and early summer, there was a decrease in the concentration of dissolved inorganic nutrients, probably due to planktonic uptake and an increment of dissolved organic nutrients, which reached their maxima at the end of the summer. Concurrently, concentration of nitrate was at its minimum value. In winter there was a maximum concentration of DIN because of DON remineralization and fresh nitrate and phosphate supply by river discharges.

The spatial characterization was less clear. The lagoon is highly dynamic, and a given site can experience quite different situations at different moments, for example, because of the tidal phase, changes in prevailing winds, or intensity of freshwater and nutrients inputs. As a result most biogeochemical properties exhibit a large spatio-temporal variability even if inner-outer and north-south gradients of nutrients, chlorophyll, and plankton abundances are usually observed (Solidoro et al. 2004). Therefore, it might be appropriate to consider not only a stiff subdivision of the lagoon based on average conditions of observed properties, but also functional and time-varying subdivisions in 'internal' versus 'marine' waters. In fact, Clusters 1 and 3 were associated mainly with 'internal' sites (e.g. Stns 2B and 9B), low salinity, and highinorganic nutrient waters, while Clusters 4 and 5 were associated mainly with 'external' sites (e.g. Stns 1M and 17B), high salinity, and low-inorganic nutrient waters. Therefore, it makes sense to consider Clusters 4 and 5 as 'marine' (dark gray in Fig. 4c) and Clusters 1 and 3 as 'internal' (light gray Fig. 4c). Cluster 2 did not exhibit a well-defined spatial characterization because of the small number of samples.

The composition of plankton communities changed in space and time, too, e.g. the number of autotrophic organisms, which may rely on abundant inorganic nutrients brought by rivers, was higher in Cluster 1 than Cluster 5, which was richer in heterotrophic organisms and thus more similar to marine waters. Similar conclusions can be made on differences between Clusters 3 and 4. Fig. 4c emphasizes how the spatial boundary between 'marine' and 'internal' conditions, and therefore the spatial extension of different plankton assemblages, is not fixed but changes in time. 
Plankton assemblages were described on a characteristic and dominant taxa basis. Characteristic taxa provided information on the occurrence of peculiar water types, and the number of characteristic taxa gave a qualitative indication of which clusters are the most favorable to the development of complex plankton communities. Dominant taxa allowed us to make some speculations on main energy paths and on the structure and functioning of food webs.

Unfortunately, and in spite of their importance in microbial food webs (Azam et al. 1983, Legendre \& Rassoulzadegan 1995), the trophic behaviour of nanoflagellates and cryptophyceae was not unambiguously identified in available data, so that they included autotrophic, mixotrophic, and heterotrophic organisms. The 2 groups were, however, considered in our analysis, because they still may provide some suggestions on the relative importance of the smallest plankton organisms in fuelling energy towards higher trophic levels. Similarly there was no information on prevailing trophic behaviour at the time of sampling for mixotrophic organisms, e.g. Strombidium spp. and Mesodinium rubrum. However, we believe that, in a multitrophic analysis, a clear identification of single-species trophism, while useful for interpretation, is not crucial.

In Fig. 5 a scheme is presented for each of the 5 typical situations identified by the classification procedure. Each scheme provides a synthetic graphical representation of the plankton community structure by indicating the main biotic components (dominant taxa), ordered from both a dimensional and a trophic perspective, and by drawing more likely trophic pathways inside the food web. The schemes also provide a qualitative description of the abiotic conditions for each plankton community.

The analysis of plankton assemblages, together with the variation in time and space of biogeochemical properties, gave the following ecological description of cluster succession. In late winter to early spring the increase in the photoperiod and high loads of dissolved inorganic nutrients brought mainly by high river discharges set up the proper conditions for an early diatom bloom. The maximum oxygen saturation values and the presence of some very large diatoms in Cluster 1 provided evidence of this bloom, even if chl a values were not very high (Table 1 ). This is the only community in which the number of dominant autotrophs was higher than the number of dominant heterotrophs and it appeared to be the only situation in which the system was clearly dominated by a herbivorous web (Legendre \& Rassoulzadegan 1995). The lack of dominant microplankton consumers and the low number and low median abundances of dominant species (Table 3) suggest that energy and biomass fluxes were modest. Furthermore, the number of connections between the microbial and the grazing food webs (Fig. 5, Cluster 1) were quite low. The simplest and most efficient path connecting primary producers to top predators went from abundant primary producers, e.g. Skeletonema costatum and Mesodinium rubrum, to the stock of nauplii of copepods and to adult Acartia clausi and Paracalanus parvus. Cannibalism is common among copepods (Turner 2004); thus, abundant nauplii of copepods could be another source of food for adult copepods.

In May the reduction in the supply of dissolved inorganic nutrients from rivers (Table 1), the depletion of nutrients due to early phytoplankton blooms, and seasonal warming abiotic conditions for a new assemblage (Fig. 5, Cluster 2). In this community the number of dominant plankton taxa (Table 3) was higher than in Cluster 1, suggesting that biomass and energy fluxes through the food webs were more relevant than in the previous months. Concentration of DOP, POC and chl a increased, and high abundance of nanoflagellates, cryptophyceae, and mixotrophic and heterotrophic microplankton revealed active circulation in the microbial loop (Liu et al. 2005) and the occurrence of major energy transfers from microbial food webs towards higher trophic levels.

The large-sized Mesodinium rubrum and large diatoms competed for nutrients and constituted the main food for top plankton consumers, whereas smaller diatoms were the most probable food source for heterotrophic microplankton, especially ciliates. These organisms in turn likely represent an important source for copepods in environments where particle concentration is high (Liu et al. 2005), as in our case. Tintinnopsis nana, which feeds on autotrophic flagellates and small diatoms, and copepods nauplii also contributed to biomass and energy transfers between the microbial and the grazing food webs. Trophic pathways from primary producers to top consumers were less efficient than in Cluster 1, due to a higher number of trophic connections (Fig. 5, Cluster 2).

Cluster 3, present in early summer, was crucial for the entire lagoon system productivity. This was the assemblage with the highest number of dominant (Fig. 5, Cluster 3) and characteristic taxa (Table 2) and the highest number of dominant diatoms. The system's biodiversity and connectivity increased to reach a fully developed multivorous food web (Legendre \& Rassoulzadegan 1995), characterized by both abundant small organisms involved mainly in the microbial loop and abundant larger organisms involved mainly in the herbivorous food web. Concentrations of DOP, DOC, POC, chl $a$, and phaeopigments were at their highest levels (Table 1), confirming both high photosynthetic and grazing activity. The cluster was present in the innermost areas of the lagoon, where moderate con- 


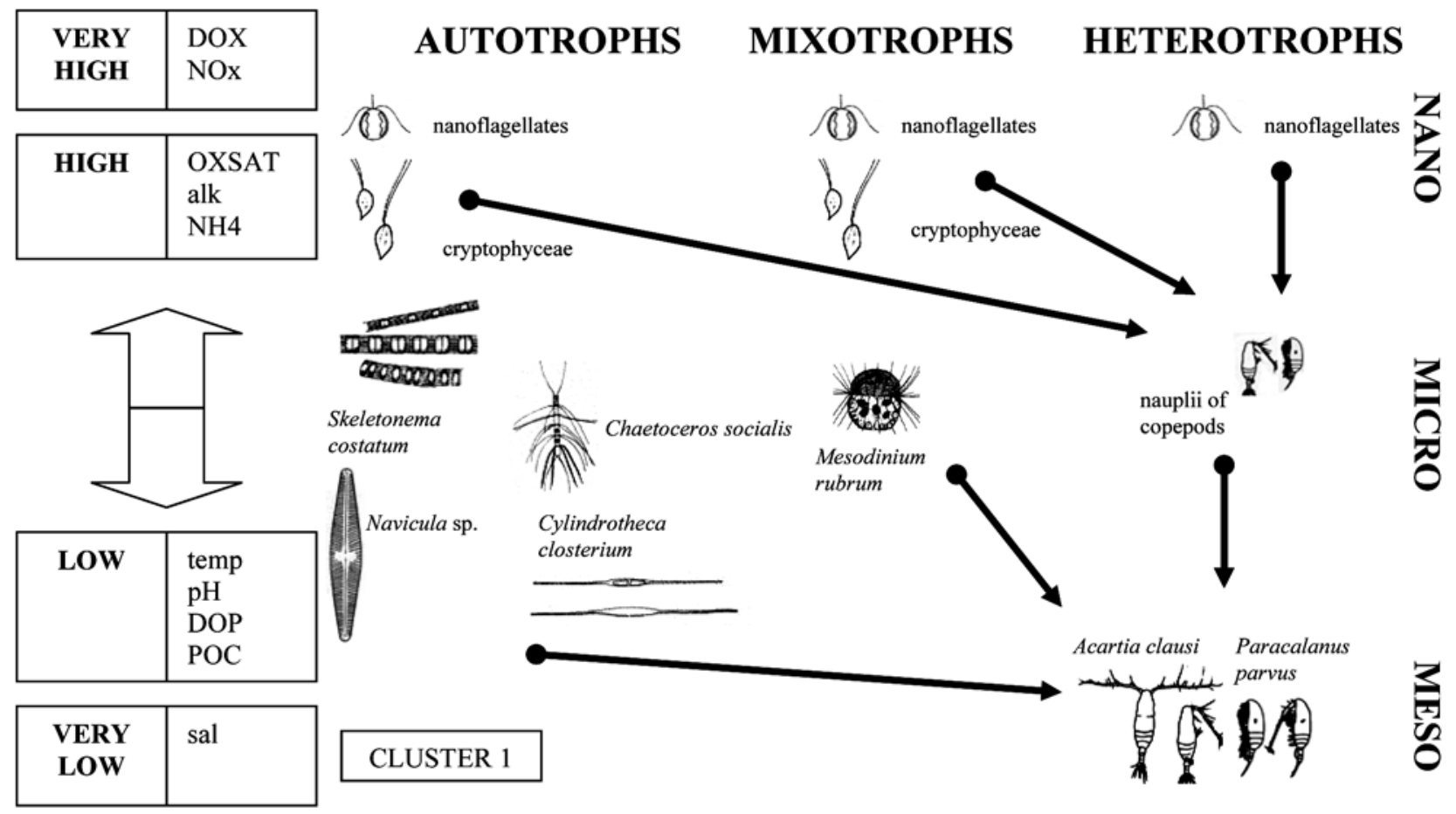

\begin{tabular}{|l|l|}
\hline HIGH & temp \\
& OXSAT \\
& pH \\
& DOP \\
& POC \\
& chl $a$ \\
\hline
\end{tabular}

\section{AUTOTROPHS MIXOTROPHS HETEROTROPHS}
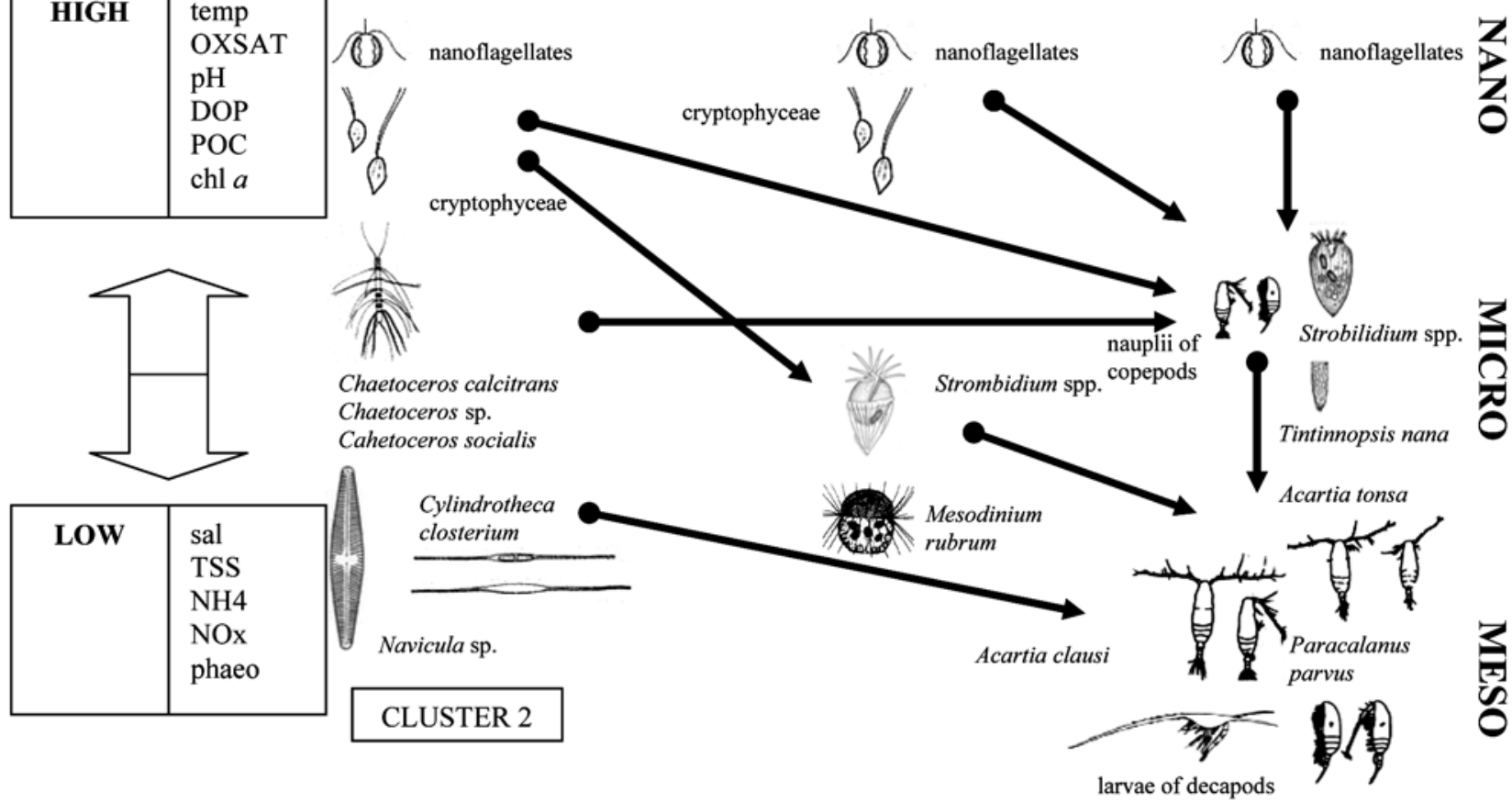

Fig. 5. Conceptual models of the trophic food webs that can be hypothesized for Clusters 1 to 5 . Only dominant taxa and relations among them are shown. On the left, medians of environmental variables characterizing each plankton community are associated with 5 classes of 20 percentiles, from 'very low' (minimum value, 20th percentile) to 'very high' (80th percentile, maximum value). Variables falling in the middle class are not shown. Abbreviations defined in Table 1 


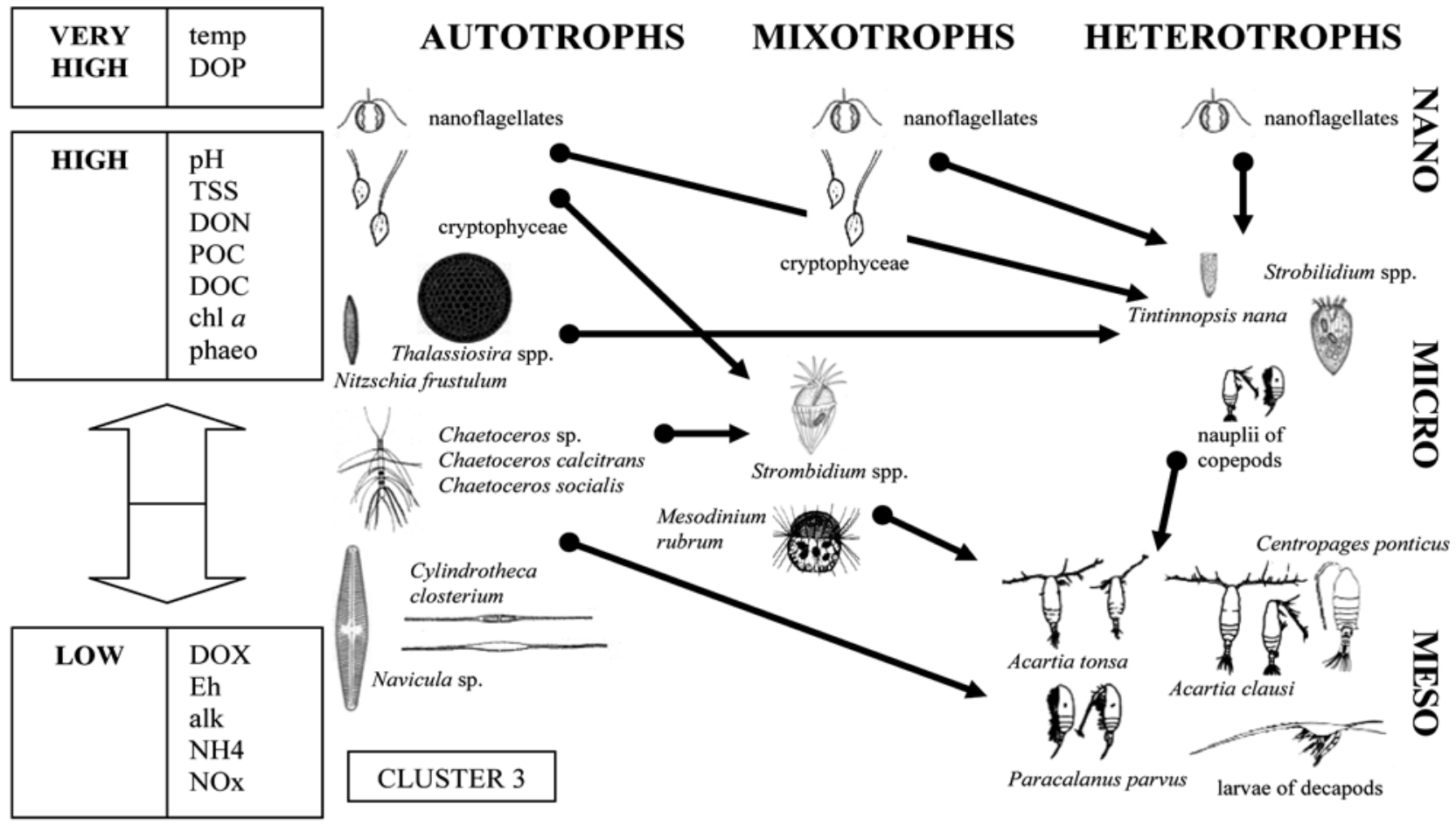

\begin{tabular}{|l|l|}
\hline VERY & sal \\
HIGH & DON \\
\hline
\end{tabular}

\section{AUTOTROPHS MIXOTROPHS HETEROTROPHS}

\begin{tabular}{|l|l|}
\hline HIGH & temp \\
& Eh \\
& alk \\
& TSS \\
& DOP \\
& POC \\
& chl $a$ \\
& phaeo \\
\hline
\end{tabular}
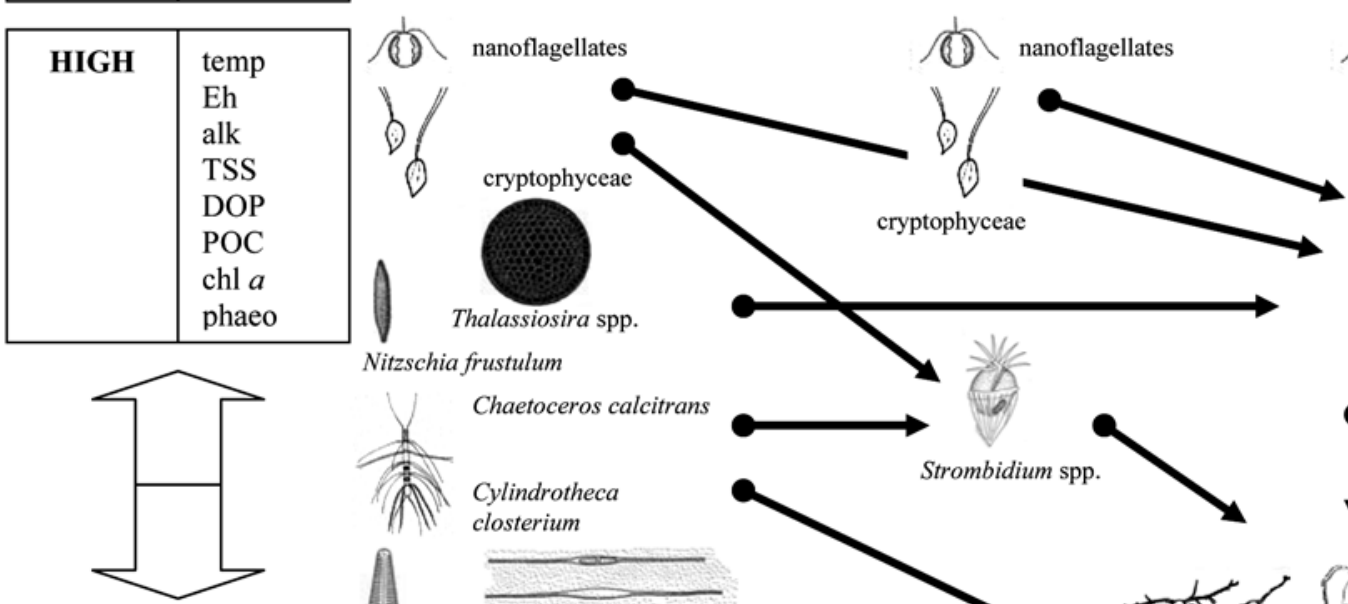

Nitzschia frustulum

\begin{tabular}{|c|l|}
\hline LOW & OXSAT \\
& DOX \\
& NH4 \\
& DOC \\
\hline
\end{tabular}

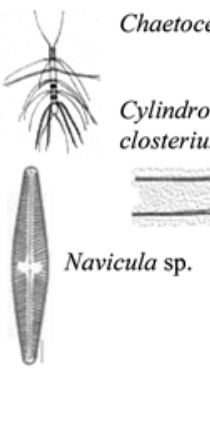

\begin{tabular}{l|l}
\hline VERY & NOx \\
LOW &
\end{tabular}

CLUSTER 4
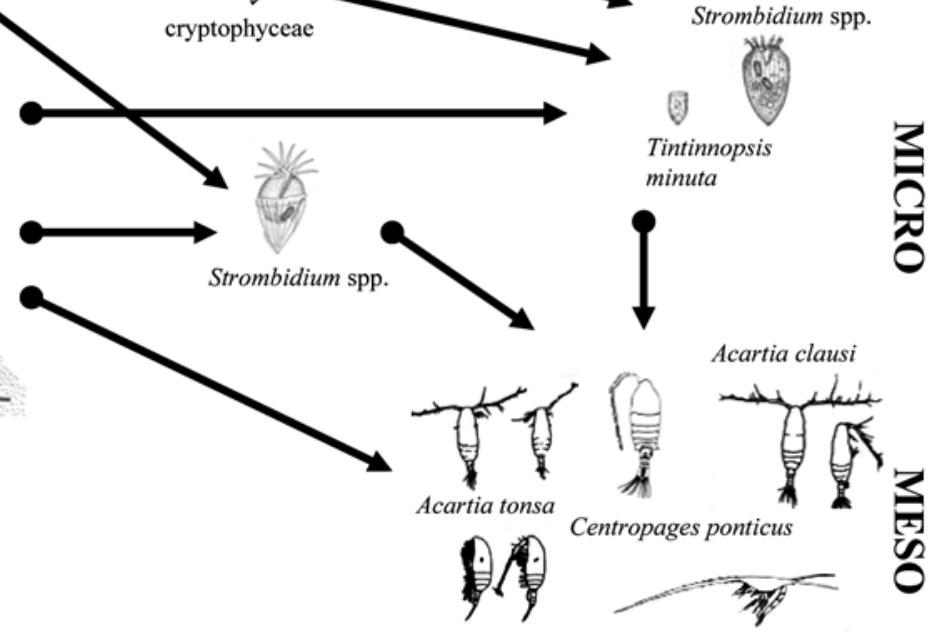

Paracalanus parvus larvae of decapods

Fig. 5 (continued) 


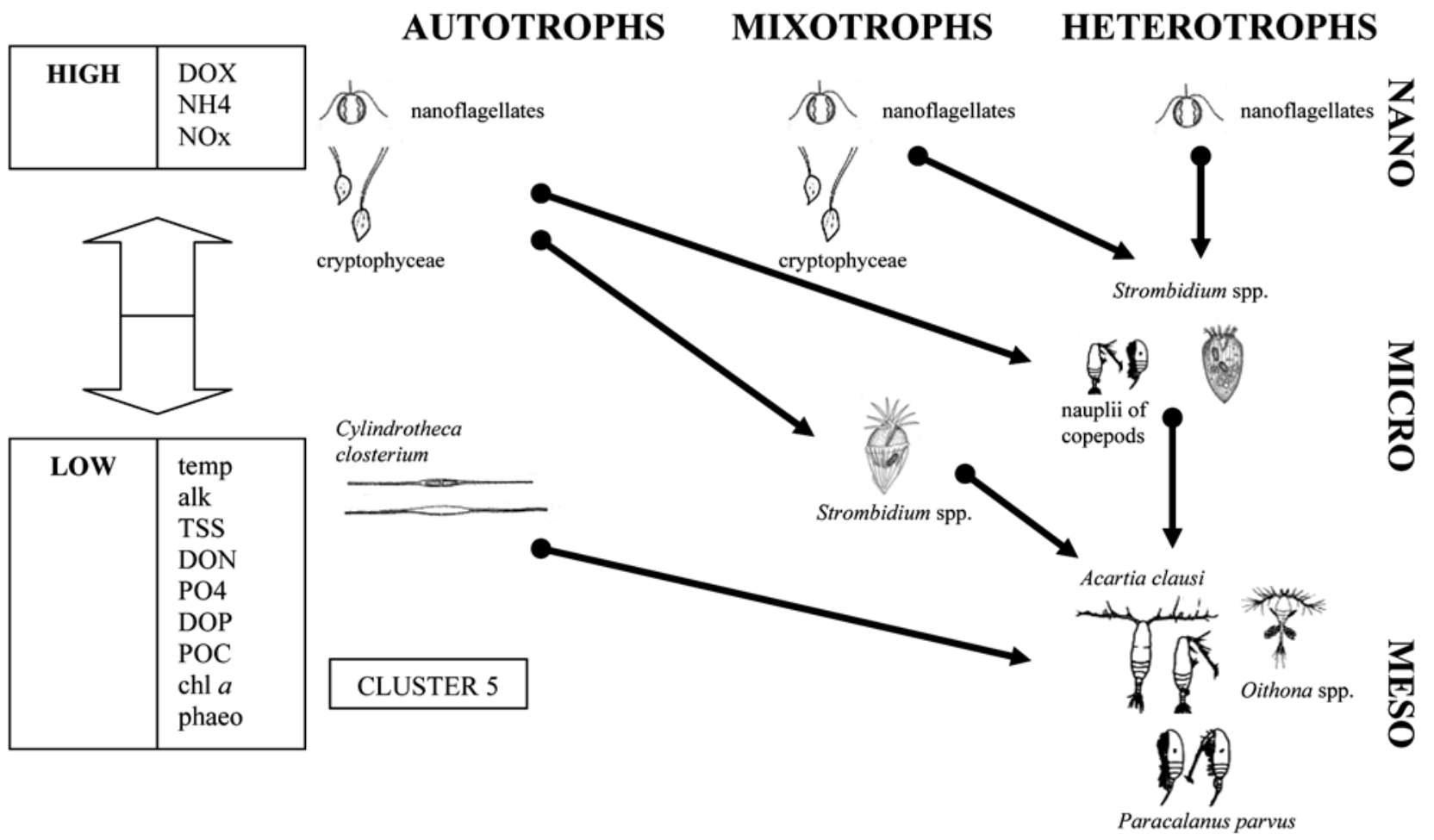

Fig. 5 (continued)

centrations of fresh inorganic nutrients from rivers were available, but high or very high concentrations of dissolved organic nutrients also revealed an increase as compared to Clusters 1 and 2 in the importance of remineralized nutrients in fuelling this community's plankton food webs. On the other hand, the accumulation of dissolved organic matter might also indicate a decoupling between primary production and demolition processes mediated by microbial activity (Thingstad et al. 1997, Fonda Umani et al. 2007). In the environment of Cluster 3, with high loads of suspended solids and organic particles, Acartia tonsa is known to be highly competitive (Purcell et al. 1994). A. tonsa could be preyed upon by larger consumers, such as other copepods and gelatinous predators (Purcell et al. 1994) and most probably constitute an important food source for fishes. In fact, juvenile fish stages migrate into the lagoon in spring, stay inside the lagoon during the summer, and migrate back to the open sea for reproduction in fall (Ravera 2000).

In late summer, along with maximum concentrations of DON, high concentrations of DOP and low values of oxygen saturation (Table 1), a decrease in the abundance of autotrophs, a decrease in biodiversity, and maximum abundances of microzooplankton were observed (Table 3). Given that inorganic nutrients and especially nitrates were low, it can be said that the food webs in Cluster 4 most probably relied mainly on abundant organic nutrients and remineralization, a fact which underlines the relevance of nutrient recycling in the Lagoon of Venice. This suggests an increase in the activities of the microbial loop and of heteretropic organisms, which can exert control on autotroph dynamics through both predation and remineralization (Duarte et al. 2000). Autotrophic processes were supported mainly by smaller organisms and by resuspended small benthic diatoms, such as Nitzschia frustulum. The central role in Cluster 4 was played by ciliates (Fig. 5, Cluster 4). Among them, the potentially mixotrophic Strombidium and the aloricate Strobilidium spp. were the most abundant heterotrophic protozooplankton organisms. In the tintinnids community, Tintinnopsis nana, which characterized Clusters 2 and 3, was replaced in Cluster 4 by T. minuta. Microheterotrophs are known to play an important role both as recyclers, because of high remineralization rates, and as consumers, since they react faster than mesozooplankton to increments in abundances of the smallest prey and channel a fraction of the production of pico- and nanoplankton to larger zooplankton. (Sieburth et al. 1978). Within the mesozooplankton community the main consumers in Cluster 4 were copepods of the genus Acartia, Paracalanus parvus, and larger organisms, such as the copepod Centropages ponticus and decapods larvae (Fig. 5, Cluster 4).

From November to January all samples were associated with Cluster 5, except Stn 2B in December and January, where Cluster 1 was observed again. In 
Cluster 5, in spite of high loads of inorganic nutrients, there were very few dominant and characteristic taxa, so that environmental conditions associated with this cluster should be considered less favourable to the growth of plankton organisms. Heterotrophic relations largely prevailed over autotrophic ones (Table 3 ), and the interactions among taxa were limited, so that food webs were the simplest and least efficient among the 5 plankton assemblages (Fig. 5, Cluster 5). Since autotrophic activity in this period was low, the biological uptake of inorganic nutrients was likely modest, and most of them just flowed out of the lagoon (Gačić \& Solidoro 2004). The only dominant diatom was Cylindrotheca closterium, but with abundances much lower than in other clusters, and nanoflagellates and cryptophyceae, even if at their minimum values, were probably the main input for pelagic trophic webs. The presence of small copepods Oithona sp., which feed on small motile prey and on organic detritus (Ribera D'Alcalà et al. 2004, Turner 2004), confirmed the prevailing heterotrophism of Cluster 5.

The above enabled us to summarize our findings in the following conceptual scheme of ecosystem functioning. In winter, the system is quite homogenous, physically controlled by river runoff and winds, phytoplankton production is very low, and the trophodynamic is likely to be supported mainly by the microbial loop. In late winter and spring, plankton activity increases, starting in the most confined areas and then spreading all over the lagoon, and an autotrophic community, fuelled by inorganic nutrients and dominated by diatoms, develops. As the season proceeds, a heterotrophic community develops as well, and the biodiversity and connectivity of the system increases, until a fully developed multivorous food web is attained in June, when the system productivity reaches its maximum. Heterotrophic processes then clearly prevail during summer, when concentrations of dissolved inorganic nutrients are low, most of the energy flows through the microbial food web, and productivity is sustained mainly by dissolved organic matter produced by remineralization of organic material. In autumn, waters rich in inorganic nutrients and poor in autotrophic organisms appear again.

Within this general picture we would like to emphasize that in shallow environments, such as the Lagoon of Venice, and particularly in the most confined areas, where water velocity is low, remineralization is relevant not only in the water column but also at the bottom. In fact, debris and organic material excreted by zooplankton sink and accumulate on the sedimentwater interface while still rich in nutrients. Here they can be transformed and remineralized by benthic and bacterial fauna. Recycled nutrients are then ready and available for benthic and pelagic primary producers if favourable light and temperature conditions for photosynthesis exist.

Furthermore, natural and anthropogenic bottom disturbances (wave motion, clam harvesting, and navigation) can cause benthic diatoms to become suspended in the water column, enriching food sources for consumers and helping to maintain sustain zooplankton even during the period of low autotrophic plankton production. It is also important to mention the role played by exchanges with the sea, since they can alter the structure of plankton communities by importing both opportunistic neritic phytoplankton species (e.g. Chaetoceros), which find favourable environmental conditions for their blooms inside the lagoon, and mesozooplankton organisms, which then exploit lagoon resources, increasing the top-down control on phytoplankton dynamics. Clearly, exchanges with marine waters can also work the other way around by diluting nutrient-rich water and exporting organisms to the neighbouring coastal waters (Bernardi Aubry \& Acri 2004).

It is worth noting that even in a year characterized by summer draught and low productivity conditions (Solidoro et al. 2006) there were complex and rich summer plankton communities. This suggests that in the Lagoon of Venice nutrient concentrations are always sufficient to build up a rich and diversified plankton community if the light and temperature requirements of single plankton species are met. This highlights the role of active remineralization inside the lagoon and of microheterotrophs in shaping the plankton community. The balance between freshwater inputs and marine water inflows is also a relevant factor, since it defines the spatial extension of environmental conditions in which plankton communities can develop.

We would also like to stress some methodological aspects. In the present study a 2-step classification procedure was used by applying traditional clustering methodologies to SOM output (Solidoro et al. 2007). This increases robustness of the results by accounting for non-uniqueness in SOM results and by taking into consideration the fact that SOM provides a local, rather than global, ordination; therefore, it is difficult to assess similarity among units far apart in the map (Park et al. 2004). In this way it was possible to move from single-species abundances to a multitrophic level and to compress the complexity of the space and time covariation of 47 taxa abundances to the variation of only one qualitative variable (presence of a given community), a fact which confirms that SOMs provide a powerful tool for pattern recognition and feature extraction.

Our results enable us to develop an objectively derived typology of ideal multitrophic plankton assemblages. These ideal assemblages can be used to capture essen- 
tial features of the structure and succession of plankton communities in the lagoon and to gain some insight into the factors shaping them. In addition, our results also provide a representation of the plankton assemblage normally associated with a given area and moment, based on available data. Since it is possible to associate new data with the trained SOM and therefore with clusters, any difference between this ideal standard and actual measurements highlights a possibly anomalous behaviour. Evaluating the magnitude of the anomaly, and whether or not it represents an improvement or worsening of ecological conditions, is something which cannot be achieved only by means of the procedure and data here presented. This would require additional information, such as the subjective identification of a number of situations already known to be of 'high' or 'low' quality. Finally, it is implicit that the availability of long-term ecological time series would increase the robustness of the results.

\section{CONCLUSIONS}

In the present study the time and space dynamics of plankton communities in a coastal lagoon was analysed by (1) objective identification of the typology of plankton assemblages in the Lagoon of Venice, (2) interpretation of each one of them from a biological perspective, in terms of dominant and characteristic taxa, their dimensions and trophic behaviour, and of more likely trophic pathways inside the food webs, (3) assessment of major biogeochemical properties associated with each plankton assemblage, and (4) description of their spatio-temporal succession.

Even though a large number of taxa, differing in dimension, trophic behaviour and taxonomic level, was considered, it was possible to objectively classify data into 5 clusters and identify for each cluster its characteristic plankton assemblage. Analysis of chemical and physical variables provided additional information for an ecological description of each cluster. Therefore, we were able to move from single taxa abundances to the community level and describe and speculate on their succession in time and space, on the structure and functioning of each plankton community, and on the external factors driving their dynamics. The results obtained indicated the importance of seasonality in ruling succession among different biocenoses and that nutrients are always sufficient to build up rich and diversified plankton communities if light and temperature requirements of plankton organisms are met. River inflows, exchanges with the sea, remineralization processes, and benthic-pelagic coupling were all important factors in shaping plankton communities and defining their spatial extension. Autotrophy pre- vailed in late winter to spring in the inner areas of the lagoon, whereas heterotrophy prevailed in late summer to early winter and generally in areas close to the inlets. Plankton communities were mainly made up of opportunistic species, with wide ecological niches, and of neritic species, entering the lagoon and exploiting its resources. Diatoms, including resuspended benthic species, dominated the autotrophic compartment. Succession from large-sized and colonial to small singlecell diatoms and from pelagic species to resuspended benthic species was observed. The results of the present study pointed out the importance of microzooplankton in the Lagoon of Venice, both as primary producers and as first-level consumers, transferring energy from small autotrophs to higher trophic levels. Copepods Acartia spp. were the most abundant mesoplankton organisms.

The ideal representation of the plankton assemblage which is normally associated with a given area and moments, can also be used as a reference term to identify and evaluate anomalous situations, as required by the implementation of the EU Water Framework Directive. Furthermore, the description of phytoplankton and zooplankton communities and their seasonal and geographical variability is specifically requested for the initial assessment of the environmental status of marine waters in the EU Marine Strategy Framework Directive. This paper, therefore, exemplifies a methodology which may also be of interest to scientists and policy makers working on other marine environments.

Acknowledgements. Data were collected as part of the Integrazione delle Conoscenze del Sistema Ecologico Lagunare (ICSEL) project, promoted by the Venice Water Authority (Magistrato alle Acque) through Servizio Ambiente - Consorzio Venezia Nuova. Thanks to Dr. M. Minocci for his help in the analysis of microzooplankton.

\section{LITERATURE CITED}

APAT IRSA-CNR (Agenzia per la Protezione dell'Ambiente e per i servizi Tecnici Istituto di Ricerca sulle Acque - Consiglio Nazionale delle Ricerche) (2003) Metodi analitici per le acque. Manuali e Linee Guida APAT, 29

APHA (American Public Health Association) (1998) 320 standard methods for the examination of water and wastewater, alkalinity, 20th edn. American Public Health Association, Washington, DC

Azam F, Fenchel T, Field JG, Gray JS, Meyer-Reil LA, Thingstad F (1983) The ecological role of water-column microbes in the sea. Mar Ecol Prog Ser 10:257-263

> Bernardi Aubry F, Acri F (2004) Phytoplankton seasonality and exchange at the inlets of the Lagoon of Venice (July 2001 - June 2002). J Mar Syst 51:65-76

Bianchi F, Acri F, Alberghi L, Bastianini M and others (2000) Biological variability in the Venice Lagoon. In: Lasserre P, Marzollo A (eds) The Venice Lagoon ecosystem: inputs and interactions between land and sea. UNESCO Paris, p 97-127 
Cloern JE, Dufford R (2005) Phytoplankton community ecology: principles applied in San Francisco Bay. Mar Ecol Prog Ser 285:11-28

Collavini F, Bettiol C, Zaggia L, Zonta R (2005) Pollutant loads from the drainage basin to the Venice Lagoon (Italy). Environ Int 31:939-947

> Cucco A, Umgiesser G (2006) Modeling the Venice Lagoon residence time. Ecol Model 193:34-51

> Duarte CM, Agustí S, Gasol JM, Vaqué D, Vazquez-Dominguez E (2000) Effect of nutrient supply on the biomass structure of planktonic communities: an experimental test on a Mediterranean coastal community. Mar Ecol Prog Ser 206:87-95

EPA (Environmental Protection Agency) (1997) Methods for determination of chemical substances in marine and estuarine environmental matrices, 2nd edn. EPA 600/R-97/072, Cincinnati, $\mathrm{OH}$

Facca C, Sfriso A, Socal G (2002) Changes in abundance and composition of phytoplankton and microphytobenthos due to increased sediment fluxes in the Venice Lagoon, Italy. Estuar Coast Shelf Sci 54:773-792

Fonda Umani S, Milani L (1990) Microzooplankton. In: Innamorati M, Ferrari I, Marino D, Ribera D'Alcalà M (eds) Metodi nell'ecologia del plankton marino. Nova Thalassia 11:251-263

Fonda Umani S, Del Negro P, Larato C, De Vittor C and others (2007) Major inter-annual variations in microbial dynamics in the Gulf of Trieste (northern Adriatic Sea) and their ecosystem implications. Aquat Microb Ecol 46: 163-175

Gačić M, Solidoro C (2004) Lagoon of Venice. Circulation, water exchange and ecosystem functioning. J Mar Syst 51:33-47

Gačić M, Kovačević V, Mancero Mosquera I, Mazzoldi A, Cosoli S (2005) Water fluxes between the Venice Lagoon and the Adriatic Sea. In: Fletcher CA, Spencer T (eds) Flooding and environmental challenges for Venice and its lagoon: state of knowledge. Cambridge University Press, Cambridge, p 431-444

Gibson GR, Bowman ML, Gerritsen J, Snyder BD (2000) Estuarine and coastal marine waters: bioassesment and biocriteria technical guidance. EPA 822-B-00-024. USEPA, Washington, DC

Giraudel JL, Lek S (2001) A comparison of self-organizing map algorithm and some conventional statistical methods for ecological community ordination. Ecol Model 146: 329-339

ICRAM (Istituto Centrale per la Ricerca scientifica e tecnologica Applicata al Mare) (2001) Metodologie analitiche di riferimento. Azoto e fosforo totali. ICRAM, Rome

IRSA (Istituto di Ricerca sulle Acque) (1990) Metodi di analisi per acque di mare. Quad Ist Ric Acque 59:570-571

Jeffries HP (1962) Succession of two Acartia species in estuaries. Limnol Oceanogr 7:354-364

Jongman RHG, ter Braak CJF, Van Tonngeren OFR (1995) Data analysis in community and landscape ecology. Cambridge University Press, Cambridge

Kaski S (1997) Data exploration using self-organizing maps, PhD thesis, Helsinki University of Technology

Kohonen T (1982) Analysis of a simple self-organizing process. Biol Cybern 44:135-140

Kohonen T (2001) Self-organizing maps, 3rd edn. SpringerVerlag, Heidelberg

Lawrence D, Valiela I, Tomasky G (2004) Estuarine calanoid copepod abundance in relation to season, salinity, and land-derived nitrogen loading, Waquoit Bay, MA. Estuar Coast Shelf Sci 61:547-557
Legendre P, Legendre L (1998) Numerical ecology, 2nd edn. Elsevier Science BV, Amsterdam

Legendre L, Rassoulzadegan F (1995) Plankton and nutrient dynamics in marine waters. Ophelia 41:153-172

Lek S, Guégan JF (1999) Artificial neural networks as a tool in ecological modelling, an introduction. Ecol Model 120: 65-73

Liu H, Dagg MJ, Wu CJ, Chiang KP (2005) Mesozooplankton consumption of microplankton in the Mississippi River plume, with special emphasis on planktonic ciliates. Mar Ecol Prog Ser 286:133-144

Liu Y, Weisberg RH, Mooers CNK (2006) Performance evaluation of the self-organizing map for feature extraction. J Geophys Res 111:C05018. doi:10.1029/2005JC003117

Marchini A, Marchini C (2006) A fuzzy logic model to recognize ecological sectors in the Lagoon of Venice based on the benthic community. Ecol Model 193:105-118

Park YS, Céréghino R, Compin A, Lek S (2003) Applications of artificial neural networks for patterning and predicting aquatic insect species richness in running waters. Ecol Model 160:265-280

Park YS, Chon TS, Kwak IS, Lek S (2004) Hierarchical community classification and assessment of aquatic ecosystems using artificial neural networks. Sci Total Environ 327:105-122

Purcell JE, White JR, Roman MR (1994) Predation by gelatinous zooplankton and resource limitation as potential controls of Acartia tonsa copepod populations in Chesapeake Bay. Limnol Oceanogr 39:263-278

Ravera O (2000) The Lagoon of Venice: the result of both natural factors and human influence. J Limnol 59:19-30

Reynolds CS (1997) Vegetation processes in the pelagic: a model for ecosystem theory. In: Kinne O (ed) Excellence in ecology, Book 9. International Ecology Institute, Oldendorf/Luhe

Ribera D'Alcalà M, Conversano F, Corato F, Licandro $\mathrm{P}$ and others (2004) Seasonal patterns in plankton communities in a pluriannual time series at a coastal Mediterranean site (Gulf of Naples): an attempt to discern recurrences and trends. Sci Mar 68:65-83

Richardson AJ, Pfaff MC, Field JG, Silulwane NF, Shillington FA (2002) Identifying characteristic chlorophyll a profiles in the coastal domain using artificial neural network. J Plankton Res 24:1289-1303

Sieburth JMcN, Smetacek V, Lenz J (1978) Pelagic ecosystem structure: heterotrophic compartments of the plankton and their relationship to plankton size fractions. Limnol Oceanogr 23:1256-1263

Solidoro C, Pastres R, Cossarini G, Ciavatta S (2004) Seasonal and spatial variability of water quality parameters in the lagoon of Venice. J Mar Syst 51:7-18

> Solidoro C, Pastres R, Cossarini G, Melaku Canu D, Ciavatta S (2006) Order and chaos in the natural world: exploring and understanding variability in the lagoon of Venice. Int J Ecodynamics 1:1-9

Solidoro C, Bandelj V, Barbieri P, Cossarini G, Fonda Umani S (2007) Understanding dynamic of biogeochemical properties in the northern Adriatic Sea by using self-organizing maps and k-means clustering. J Geophys Res 112: C07S90

Strickland JD, Parsons TT (1972) A practical handbook of seawater analysis, 2nd edn. Fish Res Board Can Bull 167 , Ottawa

Sun Y (2000) On quantization error of self-organizing map network. Neurocomputing 34:169-193

Thingstad TF, Hagström $\AA$, Rassoulzadegan F (1997) Accumulation of degradable DOC in surface waters: Is it 
caused by a malfunctioning microbial loop? Limnol Oceanogr 42:398-404

Throndsen J (1978) Preservation and storage. In: Sournia A (ed) Phytoplankton manual. UNESCO, Paris, p 69-74

Tomas CR (1997) Identifying marine phytoplankton. Academic Press, San Diego, CA

Turner JT (2004) The importance of small planktonic copepods and their roles in pelagic marine food webs. Zool Stud 43:255-266

Utermöhl H (1958) Zur Vervollkommnung der quantitativen Phytoplankton-Methodik. Mitt Int Ver Theor Angew Limnol 9:1-38

Vesanto J, Alhoniemi E (2000) Clustering of the self-organizing map. IEEE Trans Neural Netw 11:586-600

Editorial responsibility: Matthias Seaman,

Oldendorf/Luhe, Germany
Vesanto J, Himberg J, Alhoniemi E, Parhankangas J (1999) Self-organizing map in Matlab: the SOM Toolbox. In: Proc MATLAB DSP Conf 1999, Espoo, Finland, November 16-17. Espoo, p 35-40. Available at: http://lib.tkk.fi/Diss/ 2002/isbn951226093X/article2.pdf

Zingone A, Honsell G, Marino D, Montresor M, Socal G (1990) Fitoplankton. Nova Thalassia 11:183-198

Zuliani A, Zaggia L, Collavini F, Zonta R (2005) Freswater discharge from the drainage basin to the-Venice Lagoon (Italy). Environ Int 31:929-938

Zunini Sertorio T (1990a) Campionamento dello zooplankton. Nova Thalassia 11:265-275

Zunini Sertorio T (1990b) Stima della densità zooplanktonica. Nova Thalassia 11:285-288

Submitted: October 30, 2006; Accepted: May 6, 2008

Proofs received from author(s): September 18, 2008 